\title{
Competitive Gains in Business Cooperation Networks in the State of Goiás
}

\author{
Ernane Rosa Martins ${ }^{1}$, Solange da Silva ${ }^{2}$ \\ ${ }^{1}$ Coordination of Information Technology Area, Federal Institute of Education Science and Technology Goias, Luziânia, Brazil \\ ${ }^{2}$ Department of Industrial and Systems Engineering, University of Goiás, Goiânia, Brazil
}

\section{Email address:}

ernane.martins@ifg.edu.br(E. R. Martins), solansilva.ucg@gmail.com (S. da Silva)

\section{To cite this article:}

Ernane Rosa Martins, Solange da Silva. Competitive Gains in Business Cooperation Networks in the State of Goiás. Science Journal of Business and Management. Vol. 3, No. 6, 2015, pp. 285-292. doi: 10.11648/j.sjbm.20150306.20

\begin{abstract}
This research aims to study the competitive gains of some Business Cooperation Network (BCN) selected, in the State of Goiás. This study aims to broaden the understanding of earnings and benefits provided by them. This research is characterized as qualitative and exploratory nature, and the method adopted for its implementation is the study of multiple cases. Three BCNs were analyzed in the State of Goiás As a result, between competitive gains identified in the studied BCNs, are: bargaining power, market power, prospecting opportunities, shared activities, complementarity, transactional ease, new products and services.
\end{abstract}

Keywords: Business Cooperation Networks, Competitive Gains, Corporate Earnings

\section{Introduction}

According to Silva (2015), companies are coming together with the common fi $\neg$ nalidade to transform the way to compete in the market, failing to compete with companies, and starting to compete in global markets, in groups against groups [1].

Zonta et al. (2015), confirms the importance of the participation of enterprises in organization network and confirms that such participation can enhance the competitiveness of companies through cooperation and organizational learning [2].

Interorganizational agreements and networks of business cooperation has become an important strategy for companies facing competitive disadvantages [3].

BCNs, as Balestrin and Verschoore (2008) can be defined as organizations made up of a group of formally related companies with common goals, unlimited period of existence and multiple scope of action, and forward alternatives to competitive worsening of the global economy, It aims at competitiveness through joint cooperation actions. BCNs can be understood as an organizational model that has its own formal structure with a specific coordination framework, individual property relations and cooperation practical features [4].

As Balestrin and Verschoore (2008) there are six competitive gains factors observed in the cooperation between companies networks, which are larger scale and market power, generation of collective solutions, reduced costs and risks, capital accumulation, collective learning and collaborative innovation [4].

Thus, the research question of this paper is: What are the competitive gains are provided by $\mathrm{BCN}$ studied?

The purpose of this article is to study the competitive gains of some selected BCNs, located in the state of Goias.

The proposed methodology for the development of the research was defined as a multiple case study, with exploratory, involving literature and documentary qualitative.

This work is justified by the contribution which could bring in theory, with definition, constitution and comparison of $\mathrm{BCNs}$, establishing cooperation and strengthening of the participating companies.

It is hoped with this study contribute to the academic research in four BCNs with significant economic role in the State of Goiás, experiencing the difficulties encountered in practice in companies that are part of these. Also contribute to the $\mathrm{BCN}$ own, expanding the understanding of earnings and benefits thereof.

Due to the lack of studies that take into account this issue and the empirical evidence found, this work can improve understanding of the gains of these types of cooperatives in the state of Goias.

So based on the above, this article is divided into five sections, in this present section presents besides the 
introduction, the definition of the research problem, the goal, the rationale and importance of the study and structure of this research. Section 2 presents the theoretical framework, with the formation of a conceptual and theoretical base, providing subsidies for the development of this study. Section 3 presents the method used and the technical and methodological procedures used for the study. In section 4 the analysis and discussion of the results obtained in the research are presented, performing the analysis of the studied BCNs, in order to verify the homogeneity and heterogeneity between the perceptions obtained from respondents. Finally, in section 5 shows the relationships identified between the constructs used and the cases studied in the research.

\section{Literature Review}

\subsection{Enterprise Cooperation Networks}

The concept of enterprise networks, according to Farias and Ramos (2009), corresponding to inter-organizational arrangements based on systematic links often cooperative, between formally independent companies, which give rise to a particular form of coordination of economic activities [5].

The business cooperation networks are structures arising from cooperative relationships between organizations in the pursuit of collective $[6,7,8]$.

Gnyawali and Madhavan (2001) define networks as cooperative relations between competitors involving three types of resources: a) flow Assets: resources such as money, equipment, technologies and organizational skills; b) flow information includes information and knowledge gathered by the network companies; c) status of flow: based on legitimacy, power and recognition based on the integration of the network [9].

Evidence in the literature suggests that in order to consolidate the networks need to retain its members and, preferably, capture new to achieve larger and allow further gains to its members, which can be facilitated if the network is able to create unique features that is, resources that companies can not access outside the network [10].

According to Mueller (2012), networks enable increased competitiveness and innovative capacity through exchange of experiences as well as the reduction of transaction costs, expansion of knowledge, qualified staff, access to resources and complementary capabilities, as well as a wide range of contacts and cooperating partners [11].

For the network to support the pressures of competition, the composition of three fundamental conditions are required: common goals, interaction between members and management The interaction awaken the common interests that can be explored through the administrative management [4].

Balestrin and Verschoore even claim that the purpose of cooperation networks is to bring features to provide molding of the competitive environment through an effective arrangement, fitted with unified, decentralized decisions, and that prevent firms understood within the network lose their flexibility. Since according Verschoore (2006), the network cooperation is an organization comprised of companies that have common goals, unlimited time to their existence, a governance specific and unique to regulate the relations of unique properties $[4,12]$.

The networks are characterized in the dimension of institutional arrangements, in which the hierarchical relations of cooperation between companies and between companies and the state are expressed [13].

The cooperation networks have the ability to facilitate the carrying out of joint activities and resource transaction to achieve organizational goals. Can be defined as the repeated set of transactions and sustained by relational and structural configurations equipped with dynamic borders and interconnected elements [8].

The institutionalization of norms and standards for the conduct of the network is important because the characteristics may affect the profitability of companies [14, $15,16]$. To Coff (2010), the profitability of a firm is determined by its bargaining power [17].

The cooperative networks are subject to critical events that affect the interest of the participants and the continuity of the network as well as individual organizations. [18]

According to Junior and Gonçalo settings (2010); Martin (2013); Teixeira and Teixeira (2010); Bortolaso, Verschoore, Junior (2012); BCNs can be defined as an organizational structure, formed by independent and geographically dispersed companies with a set of joints and working with coordination of actions, interaction and cooperation, sharing resources, people, technologies, information, knowledge, with the same form of action, strategy, structure and management processes, in order to build competitive capacity $[19,20,21,22]$.

\subsection{Competitive Gains Provided by the Business Cooperation Network}

It is known that the $\mathrm{BCNs}$ can generate earnings to its members. The approach that will be addressed in this research is to reference the work of Balestrin and Verschoore (2008), p. 120, which synthesizes a range of benefits such as: Bargaining power, ample trade, representativeness, credibility, legitimacy, market strength, training, business consulting, shared marketing, prospecting opportunities, credit guarantee, digital inclusion, structures marketing, shared activities, confidence in new investments, complementarity, transactional ease, productivity, opportunism limitation, expansion of trust, family ties, reciprocity, internal cohesion, socialization of information and experiences, access to new external knowledge, internal benchmarking and external, new products and services, adoption of new organizational practices, access to new markets, development of new business models [4].

According Bortolaso and Sellitto (2009), the main competitive advantages identified in networks are: advantage in negotiating and increased bargaining power; risk reduction; knowledge; information exchange; shared marketing; consulting service offerings; social relationship; qualification of teams; encouraging partnership and event organization. 
[23] These resemble the competitive attributes listed by Balestrin and Verschoore (2008) [4].

According to Aragon, Lopes and Dias (2010) there are other gains, such as the search for better price conditions with its suppliers. [24] Which is a major reason for linking businesses in networks [25]. As well as legitimacy, reputation and trust that are also competitive gains established by companies operating in network [26, 27].

By acting in networks, companies can increase their organizational reputation [26] going to be perceived as reliable companies [27].

Human and Provan (1997) identified four categories of results of cooperation networks: interorganizational exchanges, organizational credibility, access to resources and financial performance. [28]

With participation in business cooperation networks, makes it possible to access resources that can contribute to the competitive advantage of establishment of the participants in the network companies, which differ in relation to its competitors. These keeps attractive to members participating in the network (retention related) at the same time they are able to attract other companies (attracting new members). Thus, from such competitive gains tend to positively influence the relations established with suppliers, financial institutions and their customers. [29]

In smaller organizations networking is emerging as a real opportunity to strengthen them. Besides increasing the ability to attract partnerships and new businesses [4].

By becoming a robust organization, the network becomes a new alternative for trade relations, generating business opportunities before unviable. In parallel, there is the possibility of establishing partnerships with universities, technological institutes and state agencies that individual companies would have difficulties to sign [4].

The gains are important for business cooperation networks, therefore, creates new opportunities and creates new avenues for increased regional production. The government acts as a partner, creating ways to promote and regulate business. And universities and research institutions active in promoting education, research, methods and information sharing. [30]

According to Wegner and Misocsky (2010) interorganizational relationships, lead to the possibility of relational returns, which can not be generated by any of the organizations individually and can only be created through the contributions of partners in an alliance. The essence of the cooperative relationship is therefore a real possibility that the union of partners and distinctive resources they bring to the relationship to be able to generate a synergy that, in isolation, could not be obtained. [31]

The solutions offered by the networks still take the form of infrastructure and support for greater breadth actions, facilitating access to new markets and exports. The network relies on a basic infrastructure to develop their activities. Physical, human, financial and communications capabilities are key to making a network. The construction and maintenance of this infrastructure are conducted jointly from the contributions of each participant. This collective infrastructure materializes business involvement, strengthening their ties and linking them more closely to the network [4].

The formation of BCNs facilitates the management of interdependence, significantly reducing the incidence of costs and risks in associated companies. Reducing these two factors is one of the key drivers of network cooperation. And the gains that they provide refer to the advantages of split between the associated costs and risks of certain actions and investments they share. [4]

Gains occur because a company that participates in a network of cooperation is able to capture the sources of efficiency of other associated companies. Sharing the technical expertise of the partners on the production process or sales can increase both productivity, providing the exchange of information on suppliers, customers and service providers, which can guide managers to choose cheaper options [4].

Casarotto Son and Pires (. 2001, p 49), argue that networking has brought greater efficiency to help companies, achieving lasting competitive advantages such as technological innovation, management modernization, collaborative relationships of institutionalization and co-production, internationalization, search and informative analysis, among others [32].

The network assists in undertaking joint actions, allowing overall cost savings as production, information and conflict resolution between members. Networks facilitate the maturing of relations that enable access nonexistent resources in the enterprise and in some cases also to match them with available resources on the network. In these relationships, more and better resources become available to be mobilized and exploited over the network to improve the performance of associates. As the costs for the generation of resources in the company are high and even higher if purchased externally, the network complementary emerges as a great alternative [4].

A network of cooperation can make use of existing capital sources among the group of companies. It is known that strong relationship bonds tend to provide an ample stock of social capital, making a group of more productive and efficient agents in the activities it performs. As a result, one of the competitive gains of cooperation networks is their ability to generate, inside, the necessary conditions for the accumulation of capital [4].

The cooperation network has a number of advantages for the internal development of social capital, as it enables constant experiences for mutual assistance, for open space to personal contacts between entrepreneurs, to present small differences between the companies involved regarding the size and power, to distribute more equanimemente the results of the efforts made by all, for allowing frank and open discussion of problems and opportunities that involve or end up involving the business of the participants [4].

Park and Zhou (2005) report that many alliances are formed without the main focus of cost reduction, the largest order the company's participation in strategic decisions, without running the risk of being left out of partnerships, or 
improving the position in the market. It also considers the importance of strategic alliances to leverage the opportunities and face business needs to market uncertainties, with the best use of specific resources and skills alliances, as these are the most efficient way to access external resources and reduce the insecurities faced [33].

In cooperation networks, the gains related to the accumulation of social capital are due to the deepening of relations between individuals and to increase the feeling of belonging and the development of group relations other than those purely economic. As a result, it appears to be parallel to benefit opportunism limitation. Because there are several reasons for companies to cooperate, there are significant incentives for the development of opportunistic actions by the involved [4].

The Inter organizational knowledge, the one created by the interaction between organizations, constitutes one of the broadest dimensions of knowledge generation. This process begins at the individual level and through the interaction between tacit and explicit knowledge between individuals, groups and organizations, is now a more complete level of knowledge, deep and meaningful. To be effective, a synergy and stimulating environment it is necessary in which the experiences, feelings and mental images are shared [4].

According to Antunes, Balestrin and Verchoore (2010) learning has been through the sharing of ideas and experiences among the members of the network [34].

According to Adam, Oliveira and Schmidt (2008), the company networks arise through formal or informal grouping of autonomous companies, in order to perform common activities, allowing them to focus only on your business activities. These companies get advantages such as improved productivity, cost savings, resource savings, access to new markets, new technologies, hand labor and suppliers, increased bargaining power in purchasing and marketing, exchange of experiences and greater access to information, improving the industry's reputation in the region, greater access to institutions and government programs [35].

According to Balestrin and Verschoore (2014, p.529), "The network idea as a new organization is built on a shared collective organizational identity by its members, emerging from an ongoing relationship focused on generating competitive advantages over the other organizations outside the network "[36].

The cooperation networks can provide an enabling environment for effective interaction between people, groups and organizations. A space where not only knowledge, but the practices, values, processes, culture and individual differences are collectively shared in favor of a common project. Complementarity may occur due to the proximity of skills, abilities and other intangible assets, accessed directly in cooperative activities or indirectly by informality and synergy of the "network effect" between companies [4].

Knowledge sharing is one of the first benefits widely recognized by network relations. So when companies collaborate to develop a technology, the resulting knowledge will be available to all partners. Each partner can then aggregate and potentially receive a larger amount of knowledge concerning same investment made individually [4].

Amato Neto (2008) emphasizes the importance of innovation for economic development organizations and is linked to implementation of new industries, transforming the existing structure and changes in the technological paradigm [37].

Cooperative networks enable the development of collective innovation strategies and have the advantage of allowing rapid access to new technologies through its information channels [4].

It can be said that, networks, innovation stems from the ability to promote socialization and use of knowledge more intensively than in other classic formats organization [4].

As Casarotto and Pires (2001) the basis of the networks is to join efforts through the innovative capacity providing its competitive visibility. Technological innovation is necessary for the maintenance business through relationships with universities, research centers and other business organizations [32].

For a network constitutes in an effective learning environment and thus fosters innovation in associates is necessary to highlight some enablers conditions, namely: trust relationships between entrepreneurs, decentralized and less hierarchical structure, informal communication, the existence of spaces and moments that make possible the socialization of knowledge and access to new knowledge and external expertise. [4]

\section{Research Methodology}

The research is characterized as qualitative, that according to Richardson (2008), can describe the complexity of a given problem, analyze the interaction of certain variables, understand and classify dynamic processes experienced by social groups, contribute in a particular group change process and enable a greater level of depth, the understanding of the behavioral characteristics of individuals [38].

This study is also characterized as exploratory for having the purpose to provide greater flexibility in seeking information about a particular problem, aiming makes it clearer, and the construction of new ideas about the topic [39].

The most appropriate method for this research is the study of multiple or multicase cases, to study some BCNs, located in the state of Goias.

To Yin (2005) "the case study is the most comprehensive of all the designs, because it is as true of people data and paper data. Indeed, the case studies data can be obtained through analysis of documents, interviews, personal accounts, spontaneous observation, participant observation and analysis of physical artifacts. "[40].

So to meet the proposed goal, this investigative method, according to Yin (2005), "allows an investigation to preserve the holistic and meaningful characteristics of real life events" such as the case of cooperative ventures. According to this author, the case study can be used to explain causal links between different real-life situations, difficult to explain 
through qualitative research [40].

The survey was conducted in four BCNs established in Goiás, three of Goiania capital and the interior of Goiás, the town of Taquaral.

At the request of some $\mathrm{BCNs}$ to preserve their identities, they received the name $\mathrm{BCN} 1, \mathrm{BCN} 2, \mathrm{BCN} 3$ and $\mathrm{BCN} 4$. Segments of BCNs are presented in Table 1.

Table 1. Selected companies for research.

\begin{tabular}{lll}
\hline Case study & Code & Segment \\
\hline 1 & BCN1 & Real estate \\
2 & BCN2 & Drugstore \\
3 & BCN3 & Clothing Industry Fashion Int \\
4 & BCN4 & Building material \\
\hline
\end{tabular}

The networks were chosen because they were acting in the state of Goiás for over five years and are registered and formalized the Board of Trade of the State of Goiás, and have an organizational structure with at least a president, whether there's someone in the manager function or not.

Five associates of each network were selected, one of the incumbent president in the interview.

Through literature were identified and analyzed studies related to the subject ETS in order to support the study and allow discussion of the findings and their comparison with the literature.

The field research was conducted in $\mathrm{BCNs}$ through meetings requested through telephone contacts with administrators / managers to explain the nature of research and specifically identify the nature of the network. Following these contacts, meetings were scheduled for interviews, conducted in 2014, which effectively occurred with administrators / managers and four associates and two managers.

It was used content analysis to analyze strategy of research data.

According to Godoy (1995) content analysis has three stages: pre-analysis, material exploration and treatment of results [41].

In this study, the pre-analysis phase consisted of organizing the material collected during the research in $\mathrm{BCN}$, and a dynamic reading of it. In the material exploration phase was prepared tables of each individual network to facilitate the exploitation and analysis, in depth, the collected data. Finally, the treatment phase of the results consisted of a qualitative analysis, which verified the homogeneity and heterogeneity between the perceptions of members and managers of the analyzed BCNs.

The method of conjoint analysis was adopted to enable the measurement of the competitive gains of the companies involved in different segments and also allow the ranking of each of these gains in order of importance.

\section{Analysis and Discussion of the Results}

In this section we present a joint analysis of the studied $\mathrm{BCNs}$, in order to verify the homogeneity and heterogeneity between the perceptions obtained from respondents.
The analysis sought to verify the confirmation or not of the research proposition and provides subsidies to propose inferences based on empirical data and theoretical references.

It sought to analyze the $\mathrm{BCN}$ as the work of Balestrin and Verschoore (2008) [4].

To better understand the analyzes made in $\mathrm{BCNs}$ on identifying benefits and their degree of intensity in BCNs is set out in Table 2 a summary of vested benefits identified in the associated $\mathrm{BCN}$, based on the work of Balestrin and Verschoore (2008).

Table 2. Benefits analysis of business cooperation networks, according Balestrin and Verschoore.

\begin{tabular}{|c|c|c|c|c|}
\hline Benefits & BCN1 & BCN2 & BCN3 & BCN4 \\
\hline Bargaining power & $\mathrm{X}$ & $X$ & $X$ & $X$ \\
\hline Extensive trade relations & & $\mathrm{X}$ & $\mathrm{X}$ & $\mathrm{X}$ \\
\hline Representativeness & & & $X$ & $\mathrm{X}$ \\
\hline Credibility & & & & $\mathrm{X}$ \\
\hline \multicolumn{5}{|l|}{ Legitimacy } \\
\hline Market strength & $X$ & $\mathrm{X}$ & $\mathrm{X}$ & $X$ \\
\hline Capacity & & $\mathrm{X}$ & $\mathrm{X}$ & $\mathrm{X}$ \\
\hline Business consulting & & & $\mathrm{X}$ & \\
\hline Shared marketing & $\mathrm{X}$ & $X$ & $\mathrm{X}$ & \\
\hline Prospecting opportunities & $\mathrm{X}$ & $\mathrm{X}$ & $X$ & $\mathrm{X}$ \\
\hline Credit guarantee & & $\mathrm{X}$ & & \\
\hline \multicolumn{5}{|l|}{ Digital inclusion } \\
\hline Structures marketing & $\mathrm{X}$ & $\mathrm{X}$ & & $\mathrm{X}$ \\
\hline Shared activities & $\mathrm{X}$ & $\mathrm{X}$ & $\mathrm{X}$ & $\mathrm{X}$ \\
\hline \multicolumn{5}{|l|}{$\begin{array}{l}\text { Confidence in new } \\
\text { investments }\end{array}$} \\
\hline Complementarity & $\mathrm{X}$ & $\mathrm{X}$ & $\mathrm{X}$ & $\mathrm{X}$ \\
\hline Transactional facility & $\mathrm{X}$ & $\mathrm{X}$ & $\mathrm{X}$ & $\mathrm{X}$ \\
\hline \multicolumn{5}{|l|}{ Productivity } \\
\hline Limitation of opportunism & $\mathrm{X}$ & & $\mathrm{X}$ & \\
\hline Confidence expansion & $\mathrm{X}$ & & & $\mathrm{X}$ \\
\hline Family ties & & & & $\mathrm{X}$ \\
\hline Reciprocity & $\mathrm{X}$ & & & \\
\hline Internal cohesion & $\mathrm{X}$ & & $\mathrm{X}$ & $\mathrm{X}$ \\
\hline $\begin{array}{l}\text { Socialization of information } \\
\text { and experiences }\end{array}$ & & $\mathrm{X}$ & $\mathrm{X}$ & $\mathrm{X}$ \\
\hline $\begin{array}{l}\text { Access to new external } \\
\text { knowledge }\end{array}$ & & $\mathrm{X}$ & $\mathrm{X}$ & $\mathrm{X}$ \\
\hline $\begin{array}{l}\text { Internal and external } \\
\text { benchmarking }\end{array}$ & & $\mathrm{X}$ & & \\
\hline New products and services & $\mathrm{X}$ & $X$ & $\mathrm{X}$ & $\mathrm{X}$ \\
\hline $\begin{array}{l}\text { Adoption of new } \\
\text { organizational practices }\end{array}$ & & $\mathrm{X}$ & $\mathrm{X}$ & $\mathrm{X}$ \\
\hline Access to new markets & & & & $\mathrm{X}$ \\
\hline $\begin{array}{l}\text { Development of new business } \\
\text { models }\end{array}$ & & & & $\mathrm{X}$ \\
\hline
\end{tabular}

Watching the Table 2, they found themselves the following vested benefits:

Bargaining power was identified in all $\mathrm{BCN}, 100 \%$;

Large commercial relationships were identified in three of the four BCN, 75\%;

Representation was identified in two of the four $\mathrm{BCN}$, $50 \%$;

Credibility was identified in one of four $\mathrm{BCN}, 25 \%$;

Entitlement was identified in any of BCNs, $0 \%$; 
Force market has been identified in all $\mathrm{BCN}, 100 \%$;

Training was identified in three out of four $\mathrm{BCN}, 75 \%$;

Consulting company was identified in one of four $\mathrm{BCN}$, $25 \%$

Marketing shared was identified in one of four $\mathrm{BCN}, 75 \%$;

Prospecting opportunities was identified in all $\mathrm{BCN}$, $100 \%$;

Guarantee credit was identified in one of four BCN, 25\%;

Digital inclusion was identified in any of $\mathrm{BCNs}, 0 \%$;

Marketing structures were identified in three of the four BCN, 75\%;

Shared activities were identified in all $\mathrm{BCN}, 100 \%$;

Confidence in new investments was identified in any of

BCNs, 0\%;

Complementarity was identified in all $\mathrm{BCN}, 100 \%$;

Transactional facility was identified in all $\mathrm{BCN}, 100 \%$;

Productivity was identified in any of BCNs, $0 \%$;

Opportunistic limitation was identified in two of the four BCN, 50\%;

Expansion of confidence was identified in two of the four $\mathrm{BCN}, 50 \%$;

Family ties have been identified in one of four BCN, 25\%;

Reciprocity was identified in one of four $\mathrm{BCN}, 25 \%$;

Internal Cohesion was identified in three out of four BCN, $75 \%$;

Socialization of information and experience was identified in three out of four BCN, 75\%;

Access to the external new knowledge was identified in three out of four $\mathrm{BCN}, 75 \%$;

Internal and external Benchmarking was identified in one of four BCN, 25\%;

New products and services have been identified in all $\mathrm{BCN}$, $100 \%$;

Adoption of new organizational practice was identified in three out of four BCN, 75\%;

Access to new markets was identified in one of four $\mathrm{BCN}$, $25 \%$;

Development of new business models has been identified in one of four BCNs, $25 \%$.

A summary of the results in percentages of vested benefits identified in relation to the $\mathrm{BCN}$, is shown in Table 3.

Table 3. Analysis of the benefits of the business cooperation networks\%, according Balestrin and Verschoore.

\begin{tabular}{ll}
\hline Benefits & BCNs \\
\hline Bargaining power & $100 \%$ \\
Extensive trade relations & $75 \%$ \\
Representativeness & $50 \%$ \\
Credibility & $25 \%$ \\
Legitimacy & $0 \%$ \\
Market strength & $100 \%$ \\
Capacity & $75 \%$ \\
Business consulting & $25 \%$ \\
Shared marketing & $75 \%$ \\
Prospecting opportunities & $100 \%$ \\
Credit guarantee & $25 \%$ \\
Digital inclusion & $0 \%$ \\
\hline
\end{tabular}

\begin{tabular}{ll}
\hline Benefits & BCNs \\
\hline Structures marketing & $75 \%$ \\
Shared activities & $100 \%$ \\
Confidence in new investments & $0 \%$ \\
Complementarity & $100 \%$ \\
Transactional facility & $100 \%$ \\
Productivity & $0 \%$ \\
Limitation of opportunism & $50 \%$ \\
Confidence expansion & $50 \%$ \\
Family ties & $25 \%$ \\
Reciprocity & $25 \%$ \\
Internal cohesion & $75 \%$ \\
Socialization of information and experiences & $75 \%$ \\
Access to new external knowledge & $75 \%$ \\
Internal and external benchmarking & $25 \%$ \\
New products and services & $100 \%$ \\
Adoption of new organizational practices & $75 \%$ \\
Access to new markets & $25 \%$ \\
Development of new business models & $25 \%$ \\
\hline
\end{tabular}

The Table 3 results demonstrate that the benefits bargaining power, market power, prospecting opportunities, shared activities, complementarity, transactional ease, new products and services are the most identified.

To better visualize the benefits unidentified in BCNs has made the choice to select them according to their respective percentages, as shown in Table 4.

Table 4. Benefits not identified in business cooperation networks\%, according Balestrin and Verschoore.

\begin{tabular}{lll}
\hline $\mathbf{N}^{\mathbf{0}}$ & Benefits & BCNs \\
\hline 1 & Productivity & $0 \%$ \\
2 & Legitimacy & $0 \%$ \\
3 & Confidence in new investments & $0 \%$ \\
4 & Digital inclusion & $0 \%$ \\
\hline
\end{tabular}

The results of the Table 4 suggest that the benefits of legitimacy, digital inclusion, confidence in new investments and productivity, were not favorable in the studied $\mathrm{BCNs}$ because they were not identified in them.

\section{Conclusion}

The research question of this work is to verify that the competitive gains are provided by BCN studied.

So for the research and to broaden the understanding of how they are competitive gains generated by the BCNs, defined the purpose of this article was to study the competitive gains of some selected BCNs, located in the state of Goiás. In this study, four were analyzed BCNs, located in the state of Goias.

The survey results revealed some relevant points about the competitive gains provided by BCN studied, among which can be highlighted:

The benefits bargaining power, market power, prospecting opportunities, shared activities, complementarity, transactional ease, new products and services were identified prominently in BCNs studied. 
This research can bring a useful contribution to people and organizations, we can count on this study to make decisions and undertake new actions.

To continue this research is suggested:

Extension of this research using other sources of evidence. New studies involving the participation of other BCNs.

\section{References}

[1] SILVA, M. P. (2015). Multilevel approach on networks: analysis of scientific literature. R. Adm. FACES Journal, Belo Horizonte, v. 14, no. 1, p. 141-151.

[2] ZONTA, P. C.; MOLLOZZI, G. A.; JENTZ, G. J.; CARVALHO, E. C. (2015). Relationship between cooperation and organizational learning with competitiveness on a network level. Networks, Santa Cruz do Sul, v. 20, no. 1, p. 179-193.

[3] WEGNER D.; ALIEVI, R. M.; BEGNIS, H. S. M. (2015). The life cycle of small-firm networks: an evaluation of brazilian business networks. BAR, Rio de Janeiro, v. 12, no. 1, p. 39-62.

[4] BALESTRIN, A.; VERSCHOORE, J. R. (2008). Networks business cooperation: management strategies in the new economy. Porto Alegre: Bookman.

[5] FARIAS, A. S. D.; RAMOS, F. S. (2009). Business Cooperation: a case study in a network of companies organized as cooperative. Arius - Journal of Human Sciences and Arts, Vol. 15, no. 2, p. 27-41.

[6] THOMPSON, G. F. (2003). Between hierarchies and markests: the logic and limits of network form of organization. New York: Oxford University Press.

[7] TODEVA, E. (2006). Busines networks: strategy and structure. New York: Taylor \& Francis.

[8] BALESTRIN, A.; VERSCHOORE, J. R.; JUNIOR, E. R. (2010). Study Course on Interorganizational Cooperation Networks in Brazil. Magazine RAC, Curitiba, v. 14, no. 3, art. 4, p. $458-477$.

[9] GNYAWALI, D.; MADHAVAN, R. (2001). Cooperative networks and competitive dynamics: a structural embeddedness perspective. Academy of Management Review, Vol. 26, no. 1, p. 431-445.

[10] ALBERS, S.; SCHWEIGER, B.; GIBB, J. (2013). Member Acquisition and Retention of Strategic Networks. In: 37th Workshop of the Organisation Theory Interest Group Within the German Association of University Professors in Management (VHB eV), Jena, 2013. Proceedings. Jena: HBV.

[11] MUELLER, E. (2012). How to manage networks? The role of networks attributes and incentives in network governance. International Journal of Entrepreneurship and Small Business, v. 15, n. 1, p. 57-75.

[12] VERSCHOORE, JR. (2006). Interorganizational cooperation networks: Identification of attributes and benefits for a management model. Doctoral thesis presented to the Postgraduate Program in Management UFRJ, Porto Alegre.

[13] MORE, I.; CARVALHO, L. C.; AMAL, M. (2014). Networks, Innovation and Export Performance: An Institutional Approach. RAC Magazine, Rio de Janeiro, v. 18, no. 5, art. 1, p. 551-576.
[14] GULATI, R., NOHRIA, N. ZAEER, A. (2000). Strategic Networks. Strategic Management Journal. Vol. 21, n. 03, p. 203-215.

[15] CAMPBELL, A.; GOOLD, M. (1999). The collaborative enterprise: why links across the corporartion Often fail and how to make Them work. Reading: Perseus Books.

[16] ANTONELLI, C. (1995). The economics of localized technological change and industrial dynamics. Netherlands: Kluwer Academic Publishers.

[17] COFF, R. W. (2010). The Coevolution of Rent Appropriation and Capability Development. Strategic Management Journal, Vol. 31, no. 7, p. 711-733.

[18] WEGNER D.; ROSSI, G.; SCARANO, T. F. (2014). The dynamics of cooperation: a longitudinal study on enterprise networks in the furniture sector. Magazine Contemporary Economics and Management, Fortaleza, v. 12, n.1, p. 111-137.

[19] JUNIOR, E. R.; GONÇALO, C. R. (2010). Social Networks, A Relational Strategies for Diagnostic Tool for the Knowledge Creation in Local Productive Arrangements. Journal of Small and Medium Enterprises, Campo Limpo Paulista, v. 3, n. 3, p. $36-51$.

[20] MARTINS, R. (2013). Collaboration in Small Companies in Logistics Processes and Medium in clusters. Journal of Small and Medium Enterprises, Campo Limpo Paulista, v. 7, no. 2, p. 49-65.

[21] TEIXEIRA, M. C.; TEIXEIRA, R. M. (2011). Relations, Cooperation and Governance in Local Productive Arrangements: The Case of LPA Wood and Furniture of the state of Rondonia. He reads. Rev. electr. adm, v. 17, no. 1, p. 237-269.

[22] BORTOLASO, I. V; VERSChOORE, J. R.; JR, J. A. V. A. (2012). Cooperative Strategies: Evaluating Strategy Management in Small and Medium Business Network. Magazine Bras. Gest. Neg, São Paulo, v. 14, no. 45, p. 419-437.

[23] BORTOLASO, I. V; SELliTTO, M. A. (2009). Competitive advantages observed in a cooperation network for marketing sporting goods. GEPROS. Production Management, Operations and Systems, year 4, n. 2, p. 37-48.

[24] ARAGON, L. A.; LOPES, C.; DIAS, M. (2010). Cooperation networks of small and medium enterprises: competitive factors applied in a supermarket chain, In: IV Meeting of Studies on Strategies, Recife, ANPAD.

[25] AMATO NETO, J. (2000). Networks of cooperation and regional clusters: opportunities for small and medium enterprises. São Paulo: Atlas.

[26] PESÄMAA, O.; HAIR, J. F. (2007). More than friendship is required: an empirical text of cooperative firm strategies. Management Decision, vol. 45, no. 3, p. 602-615.

[27] GULATI, R.; SYTCH, M. (2008). Does familiarity breed trust? Revisiting the antecedents of trust. Managerial and Decision Economics, vol. 29, p. 165-190, Special issue.

[28] HUMAN, S. E.; PROVAN, K. G. (1997). An emergent theory of structure and outcomes in small manufacturing firm strategic networks. Academy of Management Journal, vol. 40, no. 2 , p. $368-403$. 
[29] PROVAN, K.; KENIS, P. (2008). Modes of network governance: Structure, management and effectiveness. Journal of Public Administration Research and Theory, vol. 18, p. 229-252.

[30] LUNDENBERG, H.; ANDRESEN, E. (2012). Cooperation Among Companies, Universities and Local Government in a Swedish Context. Industrial Marketing Management, n. 41, no. 3 p. $429-437$.

[31] WEGNER D.; MISOCSKY, M. C. (2010). Evaluation of small business network performance: contributions of the approach of the production of meaning. Magazine $\mathrm{O} \& \mathrm{~S}$, vol. 17, no. 53, p. 345-361.

[32] CASAROTTO, F. N.; PIRES, L. H. (2001). Networks of small and medium enterprises and local development. São Paulo: Atlas.

[33] PARK, S. M.; ZHOU, D. (2005). Firm heterogeneity and competitive dynamics in alliance formation. Academy of Management Review, Vol. 30, no. 3, p. 531-554.

[34] ANTUNES, J.; BALESTRIN, A.; VERSCHOORE, J. (2010). Practices management cooperation networks. São Leopoldo: Publisher Unisinos.
[35] ADAM, C. R.; OLIVEIRA, H. J. R.; SCHMIDT, S. (2008). Proposition indicators for evaluating performance of gaucho cooperation networks. Networks: Journal of Regional Development, Santa Cruz do Sul, v. 13, no. 3, p. 218-240.

[36] BALESTRIN, A.; VERSCHOORE, JR. (2014). Replica networks are networks or networks are organizations? RAC Magazine, Rio de Janeiro, v. 18, no. 4, p. 523-533.

[37] AMATO NETO, J. (2008). Productive Cooperation Networks and Regional Clusters: Opportunity for small and medium enterprises. 1st ed. São Paulo: Atlas.

[38] RICHARDSON, R. J. (2008). Social Research: Methods and techniques. São Paulo: Atlas, 3rd ed.

[39] GIL, A. C. (1999). Methods and techniques of social research. São Paulo: Atlas.

[40] YIN, R. K. (2005). Case Study: Planning and methods. Porto Alegre: Bookman.

[41] GODOY, A. S. (1995). Introduction to qualitative research and its possibilities. Journal of Business Administration, São Paulo, v. 35 , no. 2 , p. $57-63$. 